\title{
OCORRÊNCIA DA SÍNDROME DE BURNOUT EM PROFESSORES DO MUNICÍPIO DE PAULISTA - PERNAMBUCO
}

\section{ARTIGO ORIGINAL}

CAMPOS, Lucilo Chagas Souza ${ }^{1}$

CAMPOS, Lucilo Chagas Souza. Ocorrência da Síndrome De Burnout em professores do Município de Paulista - Pernambuco. Revista Científica Multidisciplinar Núcleo do Conhecimento. Ano 04, Ed. 07, Vol. 08, pp. 74-85. Julho de 2019. ISSN: 2448-0959

\section{RESUMO}

O objetivo deste estudo foi analisar se professores da rede pública municipal de Paulista, e professores da rede particular possuem diferentes dimensões de burnout (exaustão emocional, despersonalização e realização profissional), como também procurou verificar se variáveis demográficas, profissionais e laborais associam-se às dimensões de burnout de forma diferenciada nesses dois grupos. A amostra, do tipo conveniência, foi composta por 100 professores do ensino fundamental, onde todos eles foram de escolas da rede municipal, sendo esses profissionais exclusivos de cada rede. Foi utilizado como instrumento o Maslach Burnout Inventory (MBI), e um questionário elaborado para estudar as variáveis. Os resultados obtidos revelaram que estatisticamente os dois grupos possuem diferentes dimensões de burnout, como também se verificou que tais dimensões associaram-se às variáveis de forma distinta nesses grupos.

Palavras-chave: Professores, Burnout, município, Paulista.

\footnotetext{
${ }^{1}$ Graduado em Biologia pela Fundação de Ensino Superior de Olinda -FUNESO, Mestre em Ciências da Educação e Multidisciplinaridade pela Universidade Gama Filho.
} 


\section{INTRODUÇÃO}

Não importa a profissão que atue, o estresse profissional faz parte do dia a dia num mundo cada vez mais competitivo e que exige ainda mais de seu profissional. A Síndrome de Burnout é uma das várias consequências deste ritmo profissional atual: um completo estado de tensão emocional e estresse provocado por condições de trabalho desgastantes. O próprio termo "burnout" demonstra que esse desgaste danifica aspectos físicos e psicológicos da pessoa. Afinal, traduzindo do inglês, "burn" quer dizer "queima" e "out" significa "exterior".

Os sintomas físicos da Síndrome estão associados ao desgaste humano onde prevalecem a cefaleia, insônia, entre outros. As consequências desta síndrome são muito graves chegando até a morte do indivíduo por motivo da depressão, dependência de drogas e as frustrações tanto no âmbito familiar quanto no ambiente profissional, onde o mesmo é mais comum.

Segundo Medeiros (2011) Na profissão da docência, essas mudanças afetam diretamente na reestruturação e reformas dos sistemas educativos, afetando o professor, o trabalho que desempenha, como também as suas relações profissionais e sociais, com visíveis repercussões na saúde e qualidade de vida e tendo em vista o que foi mencionado, acredita-se que o profissional da docência se expõe a fatores estressantes constantemente que, se persistirem, pode levar à Síndrome de Burnout.

Sendo assim, o objetivo geral deste trabalho é expor a síndrome de Burnout como um problema que está em evidência em professores da rede municipal de Paulista, PE. Tendo como objetivo específico:

- Identificar as principais características da síndrome de Burnout em professores;

- Descrever os sintomas, as causas e as consequências que podem estar relacionadas à síndrome;

- Indicar propostas de intervenção com a finalidade de diminuir o nível de estressados profissionais na área de docência; 
O presente trabalho analisou e compreendeu elementos que compõe o fenômeno da Síndrome de Burnout, tomando-se por base professores da rede pública municipal de Paulista, localizada na Região Metropolitana do Recife (RMR).

De acordo com Cherniss (apud MASLACH, 1993), A Síndrome é um processo que começa de forma prolongada e com um excessivo nível de tensão que produz uma fadiga do individuo no trabalho, onde o mesmo se sente sempre exausto, irritado e de forma similar a Síndrome, tem de modo silencioso caracterizada como uma progressiva perda dos ideais e do propósito de existência no trabalho.

Existe na literatura uma lista de sintomas associados a síndrome de Burnout. Tamayo \& Trócoli (2002), entendem como uma imposição a distinção entre os sintomas e as consequências da síndrome de Burnout e, por isso, apresentam esses aspectos como manifestações classificadas em diferentes grupos, afetivos, cognitivos, comportamentais, sociais, físicos, de atitude e organizacionais.

Nas manifestações afetivas, os sentimentos mais comuns são: humor depressivo, ansiedade e os sentimentos de impotência no trabalho, seguidos de uma baixa autoestima. Esse sentimento gerado faz com que o indivíduo possua uma diminuição a sua tolerância à frustração, demonstrando irritabilidade, hipersensibilidade e comportamento hostil e desconfiada para com alunos, com os colegas e com seus supervisores.

No âmbito cognitivo, os problemas principais relatados são a falta de concentração, perda de memória, dificuldade para tomar decisões, presença de tiques nervosos, incapacidade de relaxar, agitações (NUNES 2000).

Dentre estas manifestações sociais em especial com os problemas entre colegas, subordinados, alunos, seguindo um desvio dos contatos sociais correndo o risco de se isolar do convívio dos mesmos. Uma das principais características é a diminuição social, familiar e aumentando conflitos interpessoais entre os integrantes da família segundo Maslach, citado por Tamayo \& Trócoli, (2002). E a respeito ao trabalho, as 
manifestações são a perda do foco, entusiasmo, ideal, conduzindo assim ao abandono do emprego.

De acordo com Maslach e Leiter (1999), para que se resolva o desequilíbrio entre o indivíduo e o trabalho, se faz necessário enfocar tanto o funcionário como o ambiente em que este desenvolve suas atividades. Contudo, como as fontes de desgaste se encontram mais em questões situacionais do que pessoais, é importante buscar soluções no contexto social do local de trabalho. Enfim, é de fundamental importância que sejam desenvolvidos conhecimentos sobre Burnout, de forma que suas causas, prováveis consequências e possíveis formas de prevenção, possam ser transmitidas aos profissionais. O que se tem observado, é que muitos destes, culpam pela situação em que se encontram, agravando sobremaneira o problema.

A Síndrome de Burnout é reconhecida pela Organização Mundial da Saúde e pelas leis brasileiras como doença ocupacional. Por isso, admite-se o afastamento para debelar a síndrome. O problema está na dificuldade de diagnosticar o fato que em muitas vezes é confundida com depressão corriqueira. Em modo geral, antidepressivos fornecem certo alívio superficial. Mas o tratamento compreende em mais coisas, onde não adianta se automedicar com remédios e continuar a trabalhar em ritmo frenético. É necessário sim desacelerar o trabalho e ocorrer uma mudança que pode vir por meio de psicoterapia como um exemplo, outros podem também ser citados como técnicas que podem auxiliar o tratamento como a meditação e também técnicas de relaxamento associadas ao tratamento combatem esse tipo de stress.

\section{METODOLOGIA}

Foram convocados 100 professores que lecionam na rede pública municipal de Paulista para responder o questionário. Não participaram professores vinculados a duas instituições simultâneas.

Aplicou-se um questionário TABELA 4 que foi elaborado com fins de atingir o objetivo do estudo onde havia questões referentes as variedades profissionais e laborais. 
O Maslach Burnout Inventory (MBI) foi o instrumento utilizado na pesquisa referente. De acordo com Carlotto(2003), este instrumento foi traduzido para nossa língua e validado por Benevides-Pereira (2002), onde esse inventário avalia a vivência do trabalho do indivíduo em três dimensões: exaustão emocional (8 itens), Realização Profissional (7 itens) e Despersonalização (5 itens), totalizando 20 itens. Foram utilizados valores entre 1 a 5 para avaliar a frequência de intensidade: 1- nunca; 2anualmente; 3 mensalmente; 4- semanalmente; 5- diariamente.

\subsection{CLASSIFICAÇÃO DA PONTUAÇÃO DO QUESTIONÁRIO}

De 0 a 20 pontos: nenhum indício de burnout;

De 21 a 40 pontos: possibilidades de desenvolver Burnout, o profissional deverá procurar trabalhar as recomendações de prevenção da síndrome de Burnout;

De 41 a 60 pontos: fase inicial da síndrome, o professor deverá procurar ajuda profissional para debater os sintomas pertinentes e garantir, assim, a qualidade no seu desempenho profissional e sua qualidade de vida;

De 61 a 80 pontos: a síndrome de Burnout começa a se instalar. O professor deverá procurar ajuda profissional para prevenir o agravamento dos sintomas;

De 81 a 100 pontos: O professor pode estar em uma fase considerável da síndrome, mas esse quadro é perfeitamente reversível. Procurar o profissional competente de sua confiança e inicie o tratamento.

Foi realizado inicialmente, um contato com a direção das escolas envolvidas para apresentar o objetivo do estudo, a fim de obter a autorização e o apoio para a aplicação dos instrumentos do trabalho. Após o consentimento das Instituições de Ensino, foram utilizados os intervalos de trinta minutos para explicar a pesquisa aos professores e saber quem gostaria de participar. Depois que os professores aceitaram fazer parte do estudo, foi aplicado o questionário com o propósito foi levantar as variáveis profissionais e laborais, seguido do Maslach Burnout Inventory (MBI) adaptada por Jbeili (2008) na Tabela 2. 
Em termos de prevalência, verifica-se que a dimensão com percentual mais elevado é a de baixa realização profissional e a de menor percentual é a de despersonalização conforme mostrado na Tabela 1.

Tabela 3: Quantitativo de professores com a síndrome de burnout na rede municipal de Paulista

\section{Despersonalização Realização profissional Exaustão emocional 12 55 60}

Fonte: Dados do autor

Tabela 4: Questionário preliminar de identificação da Síndrome de Burnout de Jbeili (2008).

\begin{tabular}{|c|l|c|c|c|c|c|}
\hline $\mathbf{N}^{\circ}$ & \multicolumn{1}{|c|}{ Caracteristicas psicofisicas em relação ao trabalho } & $\mathbf{1}$ & $\mathbf{2}$ & $\mathbf{3}$ & $\mathbf{4}$ & $\mathbf{5}$ \\
\hline $\mathbf{1}$ & Sinto-me esgotado(a) emocionalmente em relação as minhas aulas & & & & & \\
\hline $\mathbf{2}$ & Sinto-me excessivamente exausto ao final de um dia de trabalho & & & & & \\
\hline 3 & Levanto-me cansado(a) e sem disposição para realizar o meu trabalho & & & & & \\
\hline $\mathbf{4}$ & Envolvo-me com facilidade nos problemas dos outros & & & & \\
\hline $\mathbf{5}$ & Trato algumas pessoas como se fossem da minha familia & & & & \\
\hline $\mathbf{6}$ & Tenho que desprender grande esforço para realizar minhas tarefas laborais & & & & & \\
\hline $\mathbf{7}$ & Acredito que eu poderia fazer mais pelas pessoas assistidas por mim & & & & \\
\hline $\mathbf{8}$ & Sinto que meu salário é desproporcional às funç̃es que executo & & & & \\
\hline $\mathbf{9}$ & Sinto que sou uma referência para as pessoas que lido diariamente & & & & \\
\hline 10 & Sinto-me com pouca vitalidade, desanimado (a) & & & & \\
\hline 11 & Não me sinto realizado (a) como meu trabalho & & & & \\
\hline 12 & Não sinto tanto amor pelo meu trabalho como antes & & & & & \\
\hline 13 & Não acredito mais naquilo que realizo profissionalmente & & & & \\
\hline 14 & Sinto-me sem forças para conseguir algum resultado significante & & & & \\
\hline 15 & Sinto que estou no emprego apenas por causa do salário & & & & \\
\hline 16 & Tenho me sentido mais estressado (a) com as pessoas que atendo & & & & \\
\hline 17 & Sinto-me responsável pelos problemas das pessoas que atendo & & & & \\
\hline 18 & Sinto que as pessoas me culpam pelos seus problemas & & & & \\
\hline 19 & Penso que não importa o que eu faça nada vai mudar no meu trabalho & & & & \\
\hline $\mathbf{2 0}$ & Sinto que não acredito mais na profissão que exerço & & & & \\
\hline
\end{tabular}

Fonte: Autor 


\section{RESULTADOS}

Dentre os $100(\mathrm{cem})$ professores selecionados para o estudo, 80 (oitenta) responderam ao questionário. Dentre eles, $80 \%$ sentiam-se ameaçados em sala de aula, $45 \%$ cumpriam uma jornada de trabalho superior a 60 horas semanais e $70 \%$ estavam incluídos na faixa etária inferior a 51 anos. Desse total, 54 professores, ou seja, 67,5\% apresentavam sintomas de Burnout. A Figura 1 ilustra a ocorrência da Síndrome de Burnout entre os respectivos professores.

Figura 1. Distribuição de frequências percentuais de Burnout.

\section{Síndrome de Burnout}



Fonte: Autoral

Resultados obtidos identificaram que quanto maior a idade dos professores, maior é o sentimento de distanciamento e menor o de realização no trabalho. Com relação à carga horária, verifica-se que quanto mais elevada maior é a sensação de desgaste emocional e menor o sentimento de realização profissional. A elevação do número de alunos atendidos diariamente aumenta o desgaste emocional, o distanciamento diminui a realização profissional, conforme demonstrado na Figura 2. 


\subsection{SENTIMENTO DE AMEAÇA EM SALA DE AULA}

O fenômeno da violência nos setores da nossa sociedade vem adquirindo cada vez mais visibilidade. Os resultados obtidos na presente pesquisa evidenciam os efeitos dessa violência sobre a saúde física e psicológica desses profissionais de ensino. Do total dos participantes que sofriam com a Síndrome de Burnout, $80 \%$ se sentiam também ameaçados em salas de aula, conforme mostrado na Figura 2.

Figura 2: Distribuição de frequências percentuais do sentimento de ameaça em sala de aula.

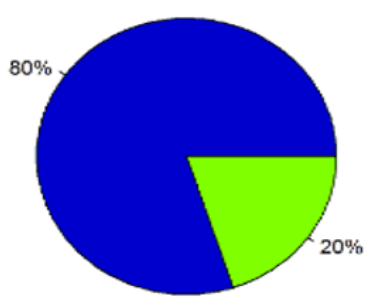

- Sentem-se ameaçados Não se sentem ameaçados

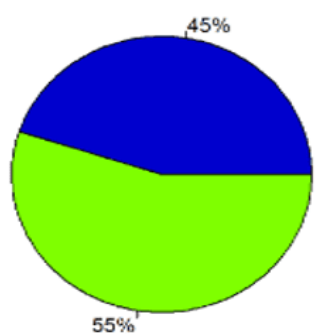

- Maior que 60h semanais Inferior a $60 \mathrm{~h}$ semanais

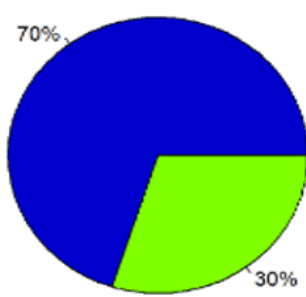

Maior que 41 anos

Fonte: Autoral

\subsection{JORNADA DE TRABALHO DO DOCENTE}

Desde o advento da revolução industrial trouxe para o nosso mundo modificações sociais, econômicas e afetando a cultura, que nem mesmo os conceitos anteriores de trabalhos e tempo de serviços conseguiram mudar: um ritmo frenético de trabalho, mais evidente em certos países do que em outros, porém, exacerbado em todo o mundo. Nos países asiáticos, uma jornada de trabalho de 16 horas diárias não é incomum - aliás, às vezes uma jornada inferior a isso é uma exceção à regra. 
No Brasil, nossa jornada preconizada é de 40 horas semanais (8 diárias e 4 aos sábados). Em grandes escolas, estas jornadas aumentam com várias horas de trânsito no deslocamento casa-serviço-casa além de aproveitar o mesmo professor para outras funções da docência na escola. Com este excesso de trabalho, chega um determinado momento em que o corpo se esgota: é a Síndrome de Burnout sendo ativada.

Analisando nos professores, a jornada de trabalho a carga horária indica ser um elemento associado à exaustão emocional. Assim, para atender mais alunos e mais atividades, o professor tem aumentado sua carga horária para em sua maioria melhorar suas condições financeiras, fazendo com que o mesmo esgote emocionalmente mais rápido.

\subsection{A FAIXA ETÁRIA E A FORMAÇÃO INSUFICIENTE DO PROFESSOR}

A idade do professor e a formação inadequada para o as demandas na atuais, se transforma em fator que começa a ser observado e registrado pelos pesquisadores. Um dos mais recentes resultados de pesquisa refere-se à idade do professor como elemento determinante para o desenvolvimento da Síndrome de Burnout.

A seguir, a Figura 3 ilustra os respectivos resultados quanto à faixa etária dos participantes. A Figura 3 aponta que $30 \%$ dos professores com a faixa etária entre 30 e 40 anos; $47,5 \%$ entre 41 e 51 anos; $16,3 \%$ entre 52 e 60 anos; e 6,2\% entre 61 e 70 anos. Nesse aspecto, a evidência mostrada nos sinaliza que os professores mais jovens, de maneira geral, fazem uso exagerado de controle em sala de aula, na tentativa de o aluno possua um comportamento adequado, enquanto isso, a utilização inapropriada desse controle da disciplina desencadeia efeitos colaterais indesejáveis como os sentimentos de exacerbação de condutas, dentre outras manifestações de comportamento que interferem no processo educacional. Os resultados da presente pesquisa sustentam também que a carga horária de trabalho excessiva contribui para o adoecimento dos profissionais que atuam nas amplas áreas da educação. 
Figura 3: Faixa etária dos participantes do projeto.

\section{Faixa etária}



Fonte: Autoral.

O objetivo inicial demonstra a intensidade da presença da Síndrome de Burnout nos professores da rede municipal e verificar os níveis de esgotamento. Os resultados obtidos confirmam que a existência do esgotamento que é algo corriqueiro nos dias de hoje está cada vez mais tirando professores das salas de aula. Esse resultado confirma os obtidos em alguns estudos brasileiros (MOURA, 1997; CARLOTTO, 2002; PEPE- NAKAMURA, 2002). Segundo Moura (1997), certos aspectos da Síndrome de Burnout estão presentes em qualquer contexto social, embora juntamente com as semelhanças, existem as manifestações que por sua vez o ocorrido de detalhes específicos e determinados pelas particularidades no ambiente de trabalho e presentes nas diferentes sociedades.

A reinterpretação positiva, que também contribui para maior realização profissional, consiste no redimensionamento do estressor a partir da modificação do estado emocional. Embora essa estratégia não esteja voltada diretamente para a resolução 
do problema, permite que o indivíduo alcance um equilíbrio emocional que, muitas vezes, é necessário como um passo anterior à ação (CARVER; SCHEIER; WEINTRAUB, 1989).

Estudos feitos por Fontana (1998) demonstram que professores que conseguem conviver ou superar as adversidades parecem pertencer a um tipo de personalidade cujas características psicológicas e outras como idade, gênero, educação, posição social e experiências passadas levam a certas variações sobre a forma como avaliar uma situação estressante e que o grau de envolvimento com as situações estressantes varia em consequência da capacidade psicofísica de resistência de cada indivíduo.

É interessante notar como essas constatações fazem sentido na análise que Hiebert e Farber (1984) realizaram em estudo com várias escolas do Reino Unido, no qual demonstraram que, embora o nível de estresse não variasse muito de escola para escola, variava amplamente dentro de cada uma delas, já que, enquanto para alguns professores os agentes estressantes eram desafios estimulantes, para outros surgiram como pressões devastadoras.

\section{CONSIDERAÇÕES FINAIS}

Utilizando como referência a literatura e os resultados desta pesquisa, foi possível observar a presença de fatores para o desenvolvimento da Síndrome de Burnout entre os professores como, por exemplo, a violência instalada no ambiente escolar, a jornada de trabalho excessiva, os baixos salários, a idade do professor associada à falta de experiência profissional e a formação continuada deficitária para o atendimento das demandas educacionais relatado pelos professores.

Segundo Maslach \& Jackson; Maslch, citados por Tamayo \& Trócoli (2002) a Síndrome de Burnout é constituída por três dimensões, dentre elas a professora G. apresentou duas, relatadas a seguir: exaustão emocional com falta de energia, sentimento de esgotamento afetivo e a baixa realização pessoal, tendo auto-avaliação negativa, falta de motivação para o trabalho. 
Nesse sentido, é válido ressaltar aspectos inúmeros vinculados ao dia-a-dia do professor que de forma direta estão relacionados à variabilidade do trabalho docente, determinado pelo modo de gestão aplicados a eles, como por exemplo as políticas educacionais, a composição e tamanho das turmas que em sua maioria são superlotadas, e infraestrutura material didático das escolas, o ato de permanecer de pé e em posição inadequada por longos períodos de tempo e além também do excesso de carga de trabalho.

Percebe-se que em seu ambiente de trabalho apesar de não demonstrar ser ameaçador, as suas necessidades de realização pessoal e profissional, não são saciadas ou supridas. Observa-se perda na interação dela com os alunos e com o ambiente de trabalho, na medida em que este ambiente contém demandas exageradas a ela, ou que ela não contém recursos adequados para enfrentar as situações que lhe são apresentadas cotidianamente (FRANÇA \& RODRIGUES,1997).

Os dados também relatam que o profissional de educação é um funcionário sujeito a inúmeros infortúnios, em função das características de sua atividade ocupacional, cada dia mais desumanizada e fora dos parâmetros, que em sua maioria por conta da desvalorização da profissão. Outros detalhes são enfatizados em literatura como responsáveis pelo grau de esgotamento no trabalho docente, seguidos pelo aparecimento da Síndrome de Burnout nos professores. Assim, os resultados da pesquisa sobre a ocorrência da Síndrome de Burnout em professores da rede municipal de ensino, poderão juntar-se a outros para subsidiar políticas públicas no sentido da instalação de serviços de caráter preventivo na rede municipal. Então, Conclui-se que tais medidas, além de contribuir para o desempenho do profissional, também têm impacto positivo na melhora da de vida do professor.

\section{REFERÊNCIAS}

ABBAGNANO, Nicola. Dicionário de Filosofia. São Paulo: Martins Fontes, 2000.

ABREU, Marina Maciel. Serviço Social e a organização da cultura: perdis pedagógicos da prática profissional. São Paulo: Cortez, 2002 
ARANTES, M. A. A. C. \& Vieira, M. J. F. (2002). Estresse. São Paulo: Casa do Psicólogo.

BENEVIDES-PEREIRA, A.M.T. (2003). O estado da arte do Burnout no Brasil. Interação Psi, 1, 4-11. Disponível http://gepeb.files.wordpress.com/2011/12/o-estadoda-arte-do-burnout-no-brasil.pdf. Acesso em 11.01.2012.

BENEVIDES-PEREIRA, A.M.T. (2009). O CBP-R em português: instrumento para a avaliação do Burnout em professores. Anais do IX EDUCERE. Curitiba. p.3927.

BENEVIDES-PEREIRA, A.M.T. Burnout em Professores: um estudo transcultural. Universidade Estadual de Maringá e Araucária. Relatório final de pesquisa. Maringá, 2004.

BENEVIDES-PEREIRA, A.M.T., Justo, T, Gomes, F.B. Silva, S.G.M. \& Volpato, D.C. (2003). Sintomas de estresse em educadores brasileiros. Aletheia, 17/18, 63-72

BRASIL. Diretrizes e normas para pesquisa envolvendo seres humanos. Resolução CNS 196/1996. Brasília: Conselho Nacional de Saúde. Ministério da Saúde, 1997.

BRASIL. Ministério da Saúde. DATASUS. Classificação Estatística Internacional de Doenças - $\quad$ CID $10 . \quad$ Disponível em: http://www.2.datasus.gov.br/DATASUS/index.phd?area=040203.

BRASIL. Ministério da Saúde. Portaria n 1339, de 18 de novembro de 1999. Lista de doenças relacionadas ao trabalho. Brasília: Ministério da Saúde, 1999.

BURKE, R. J., \& Greenglass, E. R. (1989). Psychological burnout among men and women in teaching: an examination of Cherniss model. Human Relations, 42 (3), 261-273.

BURKE, R. J., Greenglass, E. R., \& Schwarzer, R. ( 1996).Predicting teacher burnout over time: effects of works tress, social support and its consequences. Anxiety, stress and coping, 9(3), 21-275. 
BYRNE, B. M. (1993). The Maslach Burnout Inventory: Testing for factorial validity and invariance across elementary, intermediate and secondary teachers. Journal of Occupational and Organizational Psychology, 66 (3), 197-213.

CARVER, C. S; SCHEIER, M. F.; WEINTRAUB,J.K. Assessing coping strategies: a theoretically based approach. Journal of Personality and Social Psychology, v. 56 , p. 267-283, 1989

CABALLERO, L. \& MILLAN, J. (1999). La aparición del síndrome del Burnout o de estar quemado. Bulleti bimestral de comunicació interna. Secretaria General'administració i funció Pública, 2, Abril. Disponible en: teseo.es.

CARLOTTO, M. S. (2002b). Síndrome de Burnout em professores de escolas particulares de uma cidade da região metropolitana de Porto Alegre-RS. Dissertação de mestrado não publicada, Universidade Luterana do Brasil, Canoas, Brasil.

CARLOTTO, M. S. (2011). Fatores de risco da síndrome de burnout em técnicos de enfermagem. Revista da SBPH, 14(2), 7-26

CARLOTTO, M. S.; CÂMARA, S. G. Preditores da Síndrome de Burnout em professores. Revista Semestral da Associação Brasileira de Psicologia Escolar e Educacional. São Paulo, v. 11, n. 1, p. 101-110, 2007.

CARLOTTO, M. Síndrome de Burnout e Gênero e o Docentes de Instituições Particulares de Ensino.

CARVER, C. S; SCHEIER, M. F.; WEINTRAUB,J.K. Assessing coping strategies: a theoretically based approach. Journal of Personality and Social Psychology, $v$. 56 , p. 267-283, 1989

HIEBERT, B. A.; FARBER, I. Teachers stress: a literature survey with a few surprises. Canadian Journal of Education, Ottawa, v. 9, n. 1, p. 14-27, 1984 
FARBER, B. A. (1991). Crisis in education. Stress and burnout in the american teacher. São Francisco: Jossey-Bass Inc.

MASLACH, C.; SCHAUFELI, W.B.; LEITER, M.P. Job burnout. Annual Review of Psychology. v.52, p.397-422, 2001

TAMAYO, M. R., \& Tróccoli, B. T. (2002a). Exaustão emocional: Relações com a percepção de suporte organizacional e com as estratégias de coping no trabalho. Estudos de Psicologia (Natal), 7(1), 37-42.

TAMAYO, M. R., \& Tróccoli, B. T. (2002b). Burnout no trabalho. In A. M. Mendes, L. O. Borges, \& M. C. Ferreira (Eds.), Trabalho em transição, saúde em risco (pp. 4363). Brasília, DF: Editora da Universidade de Brasília.

Enviado: Junho, 2018.

Aprovado: Julho, 2019. 